\title{
A Research on Countermeasures of College Students' Safety Education from the View of Symbolic Interaction*
}

\author{
Jun Meng \\ Shandong Women's University \\ Jinan, China 250300
}

\begin{abstract}
Symbol is the foundation of social life by which people interact with each other. Furthermore, by means of symbols, people could understand others' behaviors and evaluate their influence on others as well so that a harmonious social environment could be created. From this point of view, personal security means that individuals interact effectively with the world and others to ensure their integrity and health of body and mind. In order to improve the effectiveness of safety education for college students, we must first strengthen the education of College Students' safety awareness, so that they can establish the concept of cherishing and loving their life. Secondly, waking up the initiative of College Students' self-protection, and integrating their own experience in the process of education will greatly help them to carry out selfeducation and self-protection combined with their personal backgrounds. At the same time, we should make full use of modern multimedia technology and mass media to create multimedia courses welcomed by students, and use mass media to integrate safety awareness and safety skills education into students' daily life. Finally, through the construction of extracurricular practice base, knowledge get from the classroom the can be used in specific situations and consolidated in practice.
\end{abstract}

Keywords-safety education; students; symbolic interaction; research

\section{INTRODUCTION}

Safety education is frequently considered to be a practical activity of human beings. Symbolic interactionists utilize a constellation of related theoretical frameworks that are loosely bound by the pragmatist tradition. Owing primarily to the works of William James, John Dewey, Charles Sanders Peirce, Charles Horton Cooley, and George Herbert Mead the core assumptions of American pragmatism represent a nucleus of ideas that generally characterize the unique contributions of symbolic interaction. Among the most important, pragmatism emphasizes human beings as active and creative agents; a human world that both shapes the doings of people and is fashioned by the doings of people; a determined emphasis on how subjectivity, meaning, and consciousness do not exist prior to experience, but are

*Funding Support: This paper is originated from the Scientific Research Item supported by Safe Campus Base Construction Fund provided by Shandong Women's University. emergent in action and interaction.

For these reasons, we suggest that human society is a symbolic society in which one interacts with others and things. The risk and danger means a bad cycle with the outside world to harm the integrity of the body or mental state of a person. From a general interactionist perspective, the concept of safety refers to maintain the integrity of body and mind by positive interactive relation between individuality and society. Thus, the purpose of safety education is to cultivate students' cognition of life, the value of life, the protection of life, the avoidance of risk, and the resistance to the crisis, as well as, to improve survival skills, enhance the quality of life.

This essay explores the countermeasures of college students' safety education from the view of symbolic interaction. Although the emergence and development of safety awareness has not been specifically studied by symbolic interaction theory, it reveals the social and psychological mechanism of the occurrence and development of safety awareness. Meanwhile, it help to clarify the relationship between the individual security and collective security and provides a new perspective of study on students' safety education and corresponding measures to enhance the effectiveness of our security education for college students. In what follows, I briefly review some viewpoints of theorist, including some of my own, of social interactions, safety education and multimedia. I then draw some suggestions about safety education.

\section{THE THEORETICAL BASIS FROM THE PERSPECTIVE OF SYMBOLIC INTERACTION}

\section{A. The Popular Concept of Safety}

Safety education for college students belongs to the subject of safety which specifically studies on the phenomenon, essence and change of accident rule to prevent and control or reduce accidents. Generally speaking, this subject focuses on concepts of security, epistemology and methodology of security, the principle of safe society and safe economic discipline. At present, it is generally believed that safety usually refers to the fact that all kinds of transactions do not harm to people, do not cause danger, 
losses and accidents, also, run normally and smoothly. Security is from the view of people's physical and mental demand or focus, and is talked about on things or objects related to, directly or indirectly, the state of people's physical and mental being. It is meaningless to consider the problem of security for something that is independent from people's physical and mental state.

\section{B. The Concept of Safety Basing on Symbolic Interaction}

The symbolic interaction theory is based on three simple theoretical hypotheses. The first one is that people are acting on these things according to the meaning of them. The second one is that the meaning of these things is derived or produced from the social interaction of a person with his companions. The third one is that in this process of dealing with others, he controls and corrections the meaning of these things through the process of interpreting these things.

Basing on these theoretical hypotheses, safety education is an activity to give students tools to interact positively with their world. Accordingly, the most important is to make students realize the importance of security and life to themselves. Then, self-protection skills need to be practiced to improve their ability to protect themselves and to enrich their experience of life. By this way, safety education can be integrated into student's daily behavior and ideology through personalized interpretation, and become a part of student's life ontology.

\section{The Concept of Education and Communication Based on the Theory of Symbolic Interaction}

The education in the visual threshold of the symbolic interaction is a consistent process of between the two parties through role-play. It is the basic way to result in interaction. That is to say, individuals transfer their information to others by means of ideographic symbols, by which to understand others as well. From the image of their companions, one's concept of self is built. From this point of view, education should be the emotional resonance, mutual understanding and self-identity with various symbols as the media and taking the measure of role-play in both sides of the education activities. This requires educators to use various effective educational strategies, so that the participators of education can accurately understand the meaning of various symbols, and realize the role transformation or provide conditions for them to complete role-play.

In the contemporary society, mass media has enriched and developed the practice of symbolic interaction theory and has realized the cross-cultural communication. It has successfully surpassed the restrictions of countries, nationalities, races, classes and regions by providing an equal communication platform. At the same time, the mainstream values of society have been transformed into symbols, which are quickly transmitted to the receivers through mass media, transforming the receivers' ideas and life world. However, the mass not accept the symbols without thinking, on the contrary, they interpret symbols according to their prior experience and reform the world's main thoughts by this way. The success of the mass media has set a good example for taking advantage of symbols to achieve the goal of educates their accepter.

\section{WAYS OF SAFETY EDUCATION}

\section{A. Life Consciousness Is the Premise}

In fact, the so-called security awareness is also a part of the contemporary social values; it is influenced by the mainstream values, including contemporary understanding of life. The proper security consciousness means treasuring the personal life and enhancing the quality of it, facing life with a positive attitude. In today's psychology and social sciences, the same tendencies are shared: taking human behavior as a product of various factors that affect people, they only focus on behaviors and factors that are considered to lead to behavior. However, the principle of the theory of symbolic interaction is that the meaning of things for people is the most important. Therefore, it is necessary to provide the students with the basis of safety education and learning through pointing out the significance of personal safety. By turning to a ontology view of life not as inculcation, but as the need of life continuity and values, we can be better equipped for the task of safety education. An adequate emphasis on the life of individual can motivate students' desire for self-protection and the desire to learn about safe knowledge. In the process of education, teachers and students participate in it at the sane time which is the two poles of safety education. The object of education is actively engaged in self-construction under the guidance of the value of the educator. From here we see that it is necessary to guide the safety education of college students with the correct values and consciousness of life.

\section{B. The Integration of Personal Experience}

The theory of symbolic interaction holds that meaning is produced in the process of interaction, and is the product of society, rather than the inherent property of things. In other words, the behavior of the subject is influenced by personal experience and situation. Different people have different understanding of the same thing in another situation and make it bearing different social meanings. On the other hand, the same person may have a different understanding of the same affairs because of the change of situations. When people interact with each other, they define the meaning of something to a person through their actions. The world is complex by accommodating whatever systems are relevant to a given event. What is being stated here is that social agents meaningfully engage in processes of re-interpreting and re-signifying the fleshy bodies, life, and safety? In the safe education, for instance, these systems include the experience, memory, background, history, and culture, each of them plays a vital role in the understanding to safety education and their life. Based on this, the most effective way of education is to arouse students' subjective initiative, and help students understand their ideas and skills in safety education combined with their own experience, such as the case method and situational teaching method. In this way, we can break the old cognition and experience of students, and integrate classroom- learning contents into students' 
knowledge structure to establish new knowledge system and experience system. From this view, students experience in the past life will become the placement for their new learning, such as experienced accidents, safety relief, the value of life, will affect the students' enthusiasm for learning and understanding the new knowledge. Abundant experience will stimulate the students' desire of self-protection.

\section{Give Full Play to the Advantages of Multimedia and Mass Media}

With the advent of the information society, the mass media has become an important tool for people to accept information. It haunts people's daily life and permeates all aspects of society. Stuart Hall put forward the famous coding and decoding theory. He applied Marx's economics to his own media theory and put forward that information dissemination is a complex circular system. This system consists of four stages of production, distribution, use and reproduction. In the decoding process, the audience is not passive and they have a certain ability to interpret information. Media communication is the field of multiparty forces for the contention of meaning. Mass media uses text, voice, image and other symbols as the basic unit of the framework, and conveys opinions and values to others through a series of symbols. The development of multimedia and Internet, as well as virtual reality technology, has greatly improved the effectiveness of safety education. Safety education requires diverse and creative uses of media technology to keep students engaged and to keep up with rapid developments in the ways they learn and teachers teach. Advances such as personal learning environments, gamification, and the Massive Open Online Course are beneficial for collaborative and transformative learning. At present, most colleges and universities will hold corresponding safety escape exercises and emergency evacuation rehearsal but the personalized multimedia network course is not rich enough yet. Via processes of mass-mediation, we can link safety education to other cultural products bearing the values of contemporary society that strongly influence, and often effectively define, the ways in which the public come to imagine and understand themselves in relation to the life security and survival skills structuring their society.

\section{Construction of Extracurricular Safety Practice Base}

Symbolic interaction theory believes that the interaction process between people is actually the process of "the definition of the situation". Human bodies are not simply objects in the social world with an intrinsic nature; rather, their meanings are dependent upon the actions and orientations of people towards them/selves. In short, people, as body-subjects, co-constitute shared yet fragile symbolic universes that reflect, and are a product of, embodied definitional practices and interactions. Consequently, they attach great importance to the function of role-play in social life by which the basic facts of social life is revealed and the interrelationship is adjusted to establishment a harmonious society and a good-living environment. An excellent extracurricular safety practice base and the assessment system of second classroom could enable students to consolidate and train the content of classroom-learning by real role-play. On the one hand, with the change of social life and working mode, on the other hand, the chance of application of the safety knowledge, it is not immediately available for us to practice, but if we don't apply it, there may be heavy casualties once the accident happens. The most Chinese universities will carry out regular safety drills and emergency evacuation drills every term, but safety education curriculums and teaching methods are still relatively backward, there is poor participation in the teaching, simulation training field for students is scarce. This means that we must fully tap the educational resources inside and outside the school, such as social safety museum, training base, science and technology museum, etc., and mobilize the whole society to create conditions for college students' safety education.

\section{CONCLUSION}

Symbolic interaction used to analyze the occurrence of social action deals with the safety education as a process of mutual identification and improvement aimed at the generally accepted security research including safety awareness, life attitude, safety assistance skills, safety prevention and control technology, and so on. We will turn to psychological and sociological research on safety education, and observe one's actions taken by individuals to keep their own safety in the field of human collective behavior and psychological motivation. Yet another way of contextualizing the safe education is to view it as a communication process like the mass media's way to affect its receiver, so what is the important is to translate the security knowledge into student's acceptable symbols and integrate them into the daily life of the students. Finally, the safety as a guarantee for individuals' survival and development, safety education should be included in the whole process of quality education for college students, including all kinds of majors' education such as psychological education, life education, health education and extracurricular practice.

\section{REFERENCES}

[1] FaridaFozdar, SilviaTorezani. Discrimination and Well-Being: Perceptions of Refugees in Western Australia [J]. International Migration Review, 2008:(1).

[2] Eby D W, Molnar L J. Cognitive impairment and driving safetyT [J]. Accident Analysis \&Prevention,2012,49(4): 261-262.

[3] Chen Ping,Yiqian Huang,Haicheng Feng. Study on Safety Education Work Mechanism for College Students[C]. 2012 Third International Conference on Information, Communication and Education Application(ICEA 2012):323-327.

[4] Wang Chengcheng. Analysis on the Current Situation and Practical Strategies of Safety Education for Contemporary College Students[C] International Science and Culture for Academic Contacts,2016:722724.

[5] Yuto Kitamura. The possibility of holistic safety education in Japan: From the perspective of Education for Sustainable Development (ESD)[J].IATSS Research,2014: 40-47.

[6] Caroline A. Mulvaney,Michael C. Watson,Gail Errington. Safety education impact and good practice: a review[J].Health Education, 2012:15-30. 
[7] Shuangyue Liu,Lina Chen,Juan Wang,Dan Wang,Fei Jiang. Research on Mode and System of Individualized Safety Education[J]. Procedia Engineering, 2012:281-286.

[8] Peter Shearni. Teaching practice in safety education: qualitative evidence[J]. Research Papers in Education, 2006:335-359.

[9] Han Li-fu. All-around- development Students' Evaluation-A New Assessment Facing Future Education[J]. Theory and Practice of Education, 2004(03): 22.

[10] Norman K. Denzin. Revisiting Symbolic Interaction In Music Studies And New Interpretive Works[M]. Emerald Group Publishing Limited, 2014.

[11] Dennis Waskul, Phillip Vannini. Body/Embodiment Symbolic Interaction and the Sociology of the Body[M]. Ashgate Publishing Limited, 2006. 